\title{
Identity Construction in Mathematics Learning: A Phenomenological Study of Girl Students
}

\author{
Krishna Prasad Adhikari \\ Lecturer \\ Department of Education (Mathematics) \\ Tribhuvan University, Kathmandu, Nepal
}

\begin{abstract}
This phenomenological study examined how girl students struggle in constructing their identity in mathematics learning. The concept given by Cobb and Hodge (2003) was used as a theoretical basis to explain the identity construction of girls. In addition, the process of identity construction is critically examined through a feminist perspective. Three girl students studying mathematics in Master's level were involved in in-depth interview. The data collected through interview were first transcribed, which was followed by thematic network analysis to make meaning from the information. The key finding was that students faced difficulties and struggle due to patriarchal system of society, false beliefs about mathematics and mathematics learning, and traditional and meritocratic system of teaching learning system.
\end{abstract}

Keywords: normative-identity, core-identity, personal- identity, phenomenology, patriarchy

\section{Introduction}

Studying in the same classroom, reading the same textbook, listening to the same teacher, boys and girls receive very different level of educations, why? From lower to higher education, female students are more likely to be invisible members of the classrooms in the context of Nepal. To construct identity as a mathematics student is a challenging task for girls. This article highlights the girls' experiences and struggle to construct their identity in mathematics learning. In our context, we are still concerning on the macro-phenomena of learning such as performance, school factors, home factors and social factors but there is little concerned on individualism in learning. So, I have tried to penetrate into such micro phenomena of the study which is also equally important for meaningful learning (e.g., Grootenboer \& Zevenbergen, 2008).

My interest grew in this issue as a mathematics teacher. After completed my study as the students of mathematics education from Tribhuvan University I started to teach mathematics in higher secondary level (+2), Bachelor level (B.Ed) and Masters level simultaneously. When I started 
teaching mathematics, I felt that teaching and studying is very different task, dealing different problems and issues in the field.

In my observation over a decade-long teaching career I found girls are generally in shadow region of classroom. The presence of girls in classroom is just physical, they rarely take participate in the interaction of classroom activities. Learning mathematics requires interaction between teachers, students and other agent and agency of the institutions. Martin (2006) viewed that learning is a sociopolitical activity where issues of authority, power and hierarchy affect social relations, access to ideas and positioning. Learning involves a dialectical relationship of agency and structure, which, in turn, are influenced by the socio-historical, collective experience of a group of people who shares aspects of a particular social identity. To construct the identity as mathematics students in mathematics classroom for girl students is seen very challenging task. Markus (1977) explained identities as an understood cognitive schema internally stored information and meanings serving as frameworks for interpreting experiences. This study would be useful to establish the culture of collaborative and cooperative nature of learning mathematics. Girl students who are generally behind the focus of the educational system are required for the quality and equitable education in Nepal.

It is evident that different levels of students have different cognitive structure. Even in the same class there would be students of various cognitive capabilities. The students' capabilities in learning mathematics are determined by different factors such as study habit, home support, classroom interaction and activities. These capabilities directly contribute to the identity of students. In my view learning is a sociocultural activity that encompasses interactions among people, artifacts, and ideas in socio-historical, cultural spaces that people shape and are shaped by as they act and interact within these spaces. According to Wenger (1998) leaning transforms who we are and what we can do, it is an experience of identity. We accumulate skills and information, not in the abstract as ends in themselves, but in the service of an identity. That means the formation of an identity that learning can become is a source of meaningfulness and of personal and social energy. In the above context, I aim to explore the answer the answer of following research questions:

- How do the girl students struggle to construct their identity as students in mathematics?

- How do they experience the role of institution, society, teachers and friends in making their own identity in learning mathematics?

\section{Theoretical and Conceptual Understanding}

While different theories are useful to explore the identity of learner, I rely on the concept of identity construction process discussed by Cobb and Hodge (2003). The identity construction process developed by Cobb and Hodge mainly focus on three types of developmental process: normative, core and personal identity. The identity students would have to develop to become mathematics learners corresponds to the normative identity as a doer of mathematics established in their classrooms, whereas who the students viewed themselves to be and who they wanted to become corresponds to their core identities. Personal identity can be constructed in the process of interconnecting normative and core identity. Normative identity concerns the identity that students 
would have to develop in order to become mathematical persons in a particular classroom. Since normative identity is concerned with the immediate social context of the classroom, whereas core identity is concerned with students' more enduring sense of who they are and what they want to become.

This types of identity is clearly explored by Gee(2003). According to Gee (2003) each student has a unique trajectory of participation in the activities of various groups and communities both in and out of school. Two aspects of his definition make it particularly relevant to my purpose as mathematics educators. First, it emphasizes students' active role in developing life stories. Gee acknowledges personal agency as well as the social structures inherent in the activities in which they participate. It is therefore conceivable that students with similar life histories might develop markedly different core identities at any particular point in time. Second, Gee emphasizes that students' development of new personal identities in particular setting can involve changes in their core identities. A primary consideration when documenting students' core identities in relation to schooling is to determine whether they have access to a structural rationale for learning in school and subscribe to the achievement ideology.

While core identity is concerned with students' relatively enduring sense of who they are and who they want to become, personal identity is concerned with who students are becoming in particular mathematics classroom (Cobb \& Hodge, 2003). Cobb and Hodge (2003) further explained the goal in analyzing students' personal identities is to document the extent to which they have reconciled their core identities with participation in the ongoing regeneration of the normative identity as a doer of mathematics established in their classroom. The intent in generating the data relating to the personal identity is to document 1) students' understandings of what counts as effectiveness and mathematical competence in their classroom and 2) whether and to what extent they identify with those forms of effectiveness and competence.

To conclude, people (students) reconstruct their core identities as they attempt to reconcile who they are and who they want to be with participation in particular groups and communities. As noted above, students are developing in mathematics classrooms have restricted their focus to general norms of participation and to the degree of openness of instructional tasks. So the concept discussed above on different types of identities may not be exhibited by our students due to several reasons. One of the major concerned is that how far administrators, planners and teachers help to the exposure of the students to attain such identities in learning mathematics.

Furthermore, identity construction is the social as well as individual process which has mutually reinforcing and conflicting parts. Each person has so many identities based on place, position and time. Identity is ever changing construct based on social and cultural resources which plays important role in the success and failure in social and institutional process. Indeed words are not only means of identifying. Other semiotic tools such as sounds, gestures, facial expressions, gazes are often a dominant, sometimes the only windows how student's identify themselves or 
others. In this study I will consider these aspects of identity as my conceptual understanding to explore the identity of girl students in mathematics.

\section{Methods and Procedures}

This study was based on phenomenology. I tried to explore the "common experience of different individual" in the construction of identity (e.g. Cohen, Manion, \& Morrison, 2007, p.22). I selected the classroom of the mathematics of Central Department of Education as the research cite because I have been working with my students (participants) for a long time in this institution. In addition, I have experienced some feeling of girl students regarding their presence in the classroom.

For this study, three students from three cultural backgrounds were participated in the study. The participant A was from Terai region of Nepal, where girls' education is generally taken as optional commodities. Girls are to send to the school so that good and capable person accept them for marriage. The focus is on others' status rather than focusing on making them independent and capable to explore their own identity. The participant B was from the hilly region of Nepal, where education level of people is miserable. The respondents' socioeconomic background was very low level. Her parents was illiterate, she was only the member of family who crossed the school level. The participant $\mathrm{C}$ was from Far Western part of the country where girls are taken as second graded members of family. Religious and cultural code and conduct are very crude and female has to stay in cowshed during their mensuration cycle. So the composition of participants in my study was heterogeneous and I have tried to explore the common experience in the given phenomena (e.g. Cohen, Manion, \& Morrison, 2007 p. 22).

Before data collection I made clear to the participants about some ethical issues regarding their privacy on the information they shared. I began my data collection by introducing each other. Then, I requested to my respondents to write their typical experiences being students of mathematics from the early age to the present. After analyzing their writing I developed some unstructured interview questions for each individual based on their struggle in their life. The questions I asked to individual were different in one another. I had tried to create trustworthy environment for interview where she can express her idea clearly and fairly.

The interview was recorded through my android mobile taking consent with respondent. I myself transcribed the recorded interview into text and translated into English language. I always aware on data controlling and data manipulation while transcribing the interviews. To maintain the trustworthiness and authenticity of the information member check (e.g. Cohen, Manion, \& Morrison, 2007, p. 22) was used.

After transcribing the interview of respondents I prepared the code book based on the text of the data. I made 38 different codes in total. Then, I integrated the similar codes together to make the basic themes. From the similar codes I made 23 basic themes (theme identified), after identifying the theme I prepared nine organized theme and from nine organized theme I made three global themes. On the basis of these themes I used thematic network analysis (Stirling, 2001) techniques to analyze the data. Thematic network analysis is also seems as web like structure (ibid) in which 
we can connect the global themes with the codes of the text. This stage is the first steps of data analysis (Striling, 2001) in which I started reading text through the global themes to organizing themes and to basic themes. After that I have "interpreted the pattern" and made conclusion over global theme (Strilling, 2001, p. 10).

\section{Findings and Discussion}

\section{Struggle in Patriarchal System of Society}

The basic and major challenge for the girls to construct their identity in the specific field of study is our patriarchal system of beliefs. We generally considered boys are more powerful, intelligence and genius in learning mathematics. Such type of false conception of society and family members plays the major obstructing role to construct their identity in mathematics. Most of the respondents did not seem determined to their future career. That is directly related to core identity of the student (Cabb \& Hodge, 2003). They wanted to study mathematics because society give more values to this subject because of its wider opportunities in further study but girls always struggle with their parents and relatives because they wanted to get married them at the early age. One of the respondents viewed as: "when I was at 16 years and studied in grade $X$ my father started for searching my spouse, he used to call relatives in our house and started to give torture to me for getting married". The view of this respondent indicates that the belief system in the male dominated society always forces girls to abandon from study especially in mathematics. Girls are considered as the "arkako ghar jane manchhe" then why should study this hard subject. This implies that persistence in mathematics is another struggle for girls in study. In the interview they shared the view that, " teacher interact with males students more frequently, ask them fruitful questions, and give them more precise feedback, this unequal distribution of time, energy, attention and talent boys getting better intervention than us". That means gender bias is not a noisy problem but most people even teachers are unaware of the secret sexist issues which is very important for equal participation and access in the classroom for girls.

The impact of patriarchal system of society is also seen in the information processing, communication, and coordination system of school. Respondents viewed that school management denied to share the information regarding extracurricular activities, school excursion, participation of girls students in out of school program. They always focused on boys to manage and participate in different activities of school and out of school.

After analyzing the verbatim that respondents shared school itself promoted the gender stereotype. But when girls progressed in their academic performance they started making their identity from passive receiver to active participation (e.g., Kaiser, 2005). This process of identity construction can be traced to the idea of Gee (2003) about their core identity. Each student has unique trajectory of participation in the activities of different groups and communities both in and out of school. Such participation in different activities can also help to form personal identity in the classroom as well. They can interact in every aspects of classroom. This type of identity helps to recognize individual as the particular member of classroom (e.g., Cobb \& Hodge, 2003).

\section{Beliefs in Mathematics}

Respondents expressed that they have the conception that mathematics is hard and abstract which we have to sallow the content through rote memorization. They have anxiety in mathematics 
especially in examination time. Generally, we have the beliefs that boys can do better in mathematics than girls in our context. This may be partially true because girls have to do other works together with learning but boys are free. But if we give equal chance to participate in learning activities they can also do better in mathematics (e.g., Hargreaves, 2002).

I had asked to my respondents about the causes of their low participation in the classroom. They expressed that "we generally hesitate to ask and interact with teacher because of the feeling that boys may laugh at us and tease". In this expression one respondent added that "it is partially true because boy-friends as well as teacher also react negatively to me sometime and reply that it is very simple question, oh! you don't know it.... haha". Actually this type of behavior makes students passive and humiliated. The false belief we have that boys are more talent in mathematics is playing the key role to participate in classroom. Without practicing in the classroom students cannot construct their identity as a particular mathematics student (e.g., Cobb \& Hodge, 2003).

Another important aspect that affects in beliefs on mathematics consequently to the identity construction in mathematics is anxiety. It seemed to be a problem to my respondents also. They expressed as a kind of discomfort state include dislike, worry and fear, with specific behavioural manifestations such as tension, frustration, distress, helplessness when handling mathematical tasks (e.g., Richardson \&Suinn, 1972). Sometime feelings of anxiety lead to tension, distress, shame and loss of concentrate in mathematics as well.

\section{Policies and Practices in Teaching and Learning Mathematics}

The policy that have been adopting and practicing create some biasness, obstruct participation, and create the sense of fear and failure in students. Administration also plays to increase gender imbalance in the classroom and institutions, teachers' gender and their affiliation to specific gender may shadow the other parts, peer support, focused on talented students, promotion based on merit system only, curriculum and system of evaluation creates sense of fear and failure rather than sense of success, teacher centered teaching learning style also focused only on content rather than students' interests, inquiry, roles and participation, and focusing on the mechanical style of learning rather than understanding, explaining, analyzing and presenting the contents of mathematics.

As Cobb and Hodge (2003) stated to develop every type of identity in students there should be the provision of student major roles and responsibility. One-size-fits-all system of education which we are still practicing cannot include all the students to foster their identity as the students of mathematics. One student opined that we are less in number in classroom, administration and teachers always focus on the boys to represent in every activities as well as in leadership role, so rules, regulations and activities are designed to focus on boys interest, ideas and participation, we are always in the shadow side of the classroom. The expression expressed in the interview reflects our policy and practices in educational institution. To foster the capacity of everyone's they have to get equal opportunity and access (e.g., Hargreaves, 2002). 
Curriculum and evaluation system we are practicing here are other important factors that obstruct in constructing the identity as mathematics students. Our system focused on merit, grade and result rather than understanding and application of content. Evaluation system we still practicing is as a tool to create the sense of fear and failure to the students.

\section{Conclusion}

Identity construction of girl students in mathematics learning mainly affected by patriarchal system of society, false beliefs in mathematics and traditional system of curriculum and teaching learning practices. Our cultural practices always placed girls in second position in society. Boys are superior in roles, responsibility and opportunities provided in the society. Due to different reason such as mensuration cycle, early marriage, overload in the household work load, pregnancy during the study time they could not get chance to do well in mathematics.

Our institution and institutional practices also does not promote to construct the identity of girls because administration and teacher always focus on boys in fostering the opportunities and skill. Administration does not want to give the leading role to the girls. They are not willing to give opportunities to participate in different extracurricular activities for girls. Another aspect that hinders girls to construct their identity is because of their false conception about mathematics. They believe that boys are superior and intelligence in mathematics. Girls generally do not take part in interaction in classroom because they feel that boys are more talent than us. Other factors such as anxiety in mathematics, teachers' behaviour, gestures of teachers, traditional mode of teaching learning activities also affect in forming identity of mathematics learners among girls students.

\section{References}

Cohen, L., Manion, L., \& Morrison, K. (2007). Reserch methods in education (6th ed.). New York: Routledge.

Cobb, P. \& Hodge, L. L. (2003). An interpretive scheme for analyzing the identities that students develop in mathematics classrooms. Tenth Conference of the European Association for Research on Learning and Instruction, Padua, Italy.

Gee, J.P. (2003). What video games have to teach us about learning literacy. New York: Palgrave/ Macmillian.

Grootenboer, P. \&Zevenbergen, R. (2008). Identity as a lens to understand learning mathematics: Developing a model(Proceedings of the $31^{\text {st }}$ Annual Conference of the Mathematics Education Research Group of Australasia). doi: 10.1.1.542.7129

Hargreaves, A. (2002). Teaching and betrayal. Teachers and Teaching: Theory and Practice, 8(3/4), 393-407. doi: 10.1080/135406002100000521

Martin, D. (2006). Mathematics success and failure among African-American youth: The roles of sociohistorical context, community forces, school influence and individual agency. Mahwah, New Jersey: Lawrence Erlbaum. 
Richardson, F. C. \&Suinn, R. M. (1972). The mathematics anxiety rating scale: Psychometric data. Journal of Counseling Psychology, 196 (6), 551-554.

Stirling, J. A. (2001). Thematic network: an analytic tool for qualitative research. Qualitative Research, 1(3), 385-405.

Wenger, E. (1998). Communities of practice: Learning, meaning, and identity. New York: Cambridge University Press. 